\title{
Breeding site attendance and breeding success in Phyllomedusa trinitatis (Anura: Phyllomedusidae)
}

\author{
Cameron M. Boyle, Eleanor H. Z. Gourevitch, and J. Roger Downie \\ University of Glasgow, School of Life Sciences, Graham Kerr Building. Glasgow G12 8QQ, United Kingdom. E-mail: \\ ehzgourevitch@gmail.com.
}

\begin{abstract}
Breeding site attendance and breeding success in Phyllomedusa trinitatis (Anura: Phyllomedusidae). Using a natural marker, we documented breeding site attendance patterns by males and females of the Trinidad Leaf Frog, Phyllomedusa trinitatis. We followed attendance at a cluster of three isolated ponds over 53 and 56 consecutive nights in 2016 and 2019 respectively. Most females attended only once, but for those that attended more than once we calculated an inter-nesting interval (mean 27.6 days, $N=7$ ). Males showed high pond fidelity, but some did attend at two of the ponds, always with a strong preference for one of them. Males showed three attendance patterns. A few attended on multiple consecutive nights (maximum, 19 nights); more were sporadic (one attended seven times over 46 nights with gaps of 15 and 19 days in the sequence); some attended only once (2016: 12, 2019: 15), but most were found to be present on multiple nights (2016: 38, 2019: 32). Our analysis suggested that these latter frogs were either newly recruited individuals or had been predated during the study. Our data show that rainfall has some influence on attendance. We found no relationship between male body condition and attendance pattern. In addition, there was no evidence that a particular male attendance pattern was optimal for breeding success.
\end{abstract}

Keywords: breeding success, inter-nesting interval, Phyllomedusinae, reproduction, Trinidad Leaf Frogs.

\begin{abstract}
Resumo
Atendimento do local de reprodução e sucesso reprodutivo em Phyllomedusa trinitatis (Anura: Phyllomedusidae). Utilizando um marcador natural, documentamos os padrões de atendimento do local de reprodução por machos e fêmeas da rã-folha-de-trinidad, Phyllomedusa trinitatis. Acompanhamos o atendimento de um grupo de três lagos isolados ao longo de 53 e 56 noites consecutivas em 2016 e 2019, respectivamente. A maioria das fêmeas atendeu os ninhos apenas uma vez, mas, para as que atenderam mais de uma vez, calculamos o intervalo de tempo entre as nidificações (média de 27,6 dias, $N=7$ ). Os machos mostraram grande fidelidade ao lago, mas alguns atenderam em duas lagoas, sempre com uma forte preferência por uma delas. Os machos exibiram três padrões de atendimento. Alguns atenderam em várias noites consecutivas (máximo de 19 noites); outros foram esporádicos (um atendeu sete vezes em 46 noites com intervalos de 15 e 19
\end{abstract}

Received 01 December 2020

Accepted 14 June 2021

Distributed June 2021 
dias na sequência); alguns assistiram apenas uma vez (2016: 12, 2019: 15), mas a maioria esteve presente em várias noites (2016: 38, 2019: 32). Nossa análise sugeriu que esses últimos machos eram indivíduos recém-recrutados ou tinham sido predados durante o estudo. Nossos dados mostram que a precipitação exerce alguma influência sobre o atendimento. Não encontramos qualquer relação entre a condição corporal dos machos e o padrão de atendimento. Além disso, não encontramos evidências de que um determinado padrão de atendimento dos machos fosse ótimo para seu sucesso reprodutivo.

Palavras-chave: intervalo entre nidificações, Phyllomedusinae, rã-folha-de-trinidad, reprodução, sucesso reprodutivo.

\section{Introduction}

Reproductive activity in anuran amphibians can be broadly classified into two patterns. In 'explosive' breeding, all adults arrive at the breeding site over a short period, undergo a brief period of mate selection usually involving nocturnal calling and competitive interactions by the males, before couples enter amplexus, spawn and then depart, the whole process often lasting just a few days (Wells 1997, Gottsberger and Gruber 2004). In temperate regions, breeding generally occurs only once a year, but in the tropics, it may occur several times throughout the year, depending on the weather conditions, particularly rainfall (Wells 1997, Gottsberger and Gruber 2004, Ulloa et al. 2019). Alternatively, breeding can be 'continuous' with asynchronous availability of gravid females at the breeding site over many weeks or months (Given 1988, Aichinger 1992, Wells 1997). In this pattern, which is commonly observed in the tropics, males may defend a territory and attract females to mate there (Given 1988, McCauley et al. 2000). Exceptionally, females may be territorial, usually in the defence of access to food, but mating still depends on their being ready to breed (Wells 1977, 2007, Meuche et al. 2011).

An extended breeding season creates problems for the males. Since they may not be able to predict when gravid females will appear, it might seem best for them to attend the breeding site every night. However, persistent attendance can be costly in several ways: attendance, along with calling behavior, could make an individual conspicuous to predators (Ryan et al. 1981, Lucas and Howard 1995); attendance by multiple males could increase the risk of injurious aggressive interactions; and attendance with calling could be energetically costly, and eventually debilitating if accompanied by a reduction in foraging opportunities (Wells 1977, 2007, Ryan et al. 1981, Lucas et al. 1996). These costs could all reduce the only benefit of nightly attendance, mating opportunity. Therefore, a trade-off may operate, whereby individuals attend often enough to have an increased chance of mating, but not so often as to do so at a high risk (Lucas and Howard 1995).

Phyllomedusa trinitatis Mertens, 1926, also known as the Leaf-nesting Frog and Trinidadian Monkey Frog (Kirton 2014), can be found in Trinidad and Venezuela but is not seen in Tobago (Murphy 1997, Downie et al. 2013). A terrestrial frog, its habitats are moist and include lowland forest and its edges and montane rainforest, but it has also been found in ditches located near to secondary forests (Murphy 1997, Kirton 2014). Males and females live in trees and are typically solitary, until the mating season which runs through the wet season (MayDecember) (Kirton 2014, Gourevitch and Downie 2018). Males perch on leaves or branches near water and call to attract females (Downie et al. 2013). In this time the males are territorial and will fight other males if they enter their perching site. Fighting is preceded by leg waving, but if this does not deter the competitor, males will grapple until one falls or is forced to leave the area. When females approach the 
breeding area, males, sometimes several at the same time, will attempt to mount her. When mating, a female will carry a male on her back to a suitable egg-laying site. $P$. trinitatis constructs its nests over pools of still water, folding leaves around a mass of eggs, which, when hatched, will fall into the pool of water where they will develop until metamorphosis (Downie et al. 2013). The female seals the nest with a jelly plug after the male fertilizes the eggs (Downie et al. 2013). More generally, male phyllomedusine frogs show high but not complete site fidelity, perhaps due to the unpredictable attendance of females (Wogel et al. 2006, Dias et al. 2017, Borges et al. 2018).

Previous work on phyllomedusine frogs used a variety of techniques to identify individuals including toe clipping (Wogel et al. 2005, 2006, Frost 2020), photography of variable thigh or flank markings (Oliveira et al. 2012, Borges et al. 2018, Frost 2020), and fluorescent implants (Dias et al. 2017). Oliveira et al. (2012) identified some individuals that attended their site in all three consecutive years of the study. All of these studies made valuable observations, but none followed individuals over a substantial number of consecutive nights.

Here we report on the results of a long running study of a single population of individually identified $P$. trinitatis males and females and their attendance patterns at a breeding site. We hypothesised that male attendance patterns are influenced by external factors, including predation and weather or by individual variations, including site fidelity or body condition. We hoped that by assessing both male and female attendance we could determine if one sex influences the other. We assessed (1) the attendance patterns of gravid females and how they relate to male attendance, (2) the attendance patterns of males in relation to site fidelity, weather, body condition, predation, and recruitment, and (3) male breeding success (including number of matings and number of tadpoles released from nests) in relation to attendance patterns.

\section{Materials and Methods}

\section{Study Site and Breeding Behavior}

As reported by Gourevitch and Downie (2018), the grounds of the William Beebe Tropical Research Centre ('Simla') in the Arima Valley of Trinidad's Northern Range mountains $\left(10^{\circ} 41^{\prime} 33.2^{\prime \prime} \mathrm{N}, 61^{\circ} 17^{\prime} 22.7^{\prime \prime} \mathrm{W}\right)$ contain three sets of concrete ponds, originally built for fish research, but now colonized by several frog species as breeding sites, including $P$. trinitatis. The ponds are distributed as a triangle, with the maximum distance between ponds being $60 \mathrm{~m}$. Each of the ponds is surrounded by vegetation, some of which has branches and large leaves overhanging the water. Ponds 1 and 2 (P1 and P2) are $4 \times 6 \mathrm{~m}$ and $2 \times 3 \mathrm{~m}$ respectively, are close to the Centre's buildings and receive some nocturnal illumination; Pond $3(\mathrm{P} 3)(3 \times 5 \mathrm{~m})$ is downhill a short distance within the forest and is dark at night. All the ponds are located well above the valley floor, and there are no other bodies of standing water in the vicinity. This means that all $P$. trinitatis individuals in the local population must use these ponds for breeding. The ponds are deep and shaded enough that, unless deliberately drained, they hold water all year round.

Phyllomedusa trinitatis breed throughout the rainy season, from late May or early June and continue to the end of the rainy season in December (Kenny 1966). Males call from perches on vegetation from about 20:00 h (sunset is around $18: 30 \mathrm{~h}$ ) and remain there for up to 5 hours; calls are quiet and sporadic in this species, unlike the loud continuous calls made by many chorusing frogs. Frogs are located by their call or visually using a head torch: the reflection of torchlight in their eyes helps to find the frogs, which otherwise remain well hidden amongst the leaves.

Once a pair has begun amplexus, they move together to a site suitable for nest building, generally overhanging standing water. Eggs and jelly capsules are deposited in a coherent mass on a leaf, with jelly plugs above and below the 
eggs. The leaf, often along with other leaves, is folded around the egg mass to enclose it, with generally only narrow openings leading to the jelly plugs above and below. The frogs then leave the 'nest'. Hatching into the water below occurs after about seven days (Downie et al. 2013).

\section{Breeding Site Attendance}

We made a preliminary survey of attendance patterns over 22 nights from 05 June to 06 July 2015. This was repeated more intensively in 2016 (53 consecutive nights from 14 June to 05 August) and in 2019 (56 consecutive nights from 09 June to 03 August). In 2016, surveys were conducted by a team of four observers, all of whom received training in call recognition and frog handling. A similar team surveyed in 2019. In 2016, surveys beginning at 23:00 $\mathrm{h}$ were completed by 01:00 h, at which time observations indicated that frogs began to leave the site. However, observations extended later when pairs in amplexus were found. Ponds were surveyed in the same order each night: P1, then 2, then 3, but it was not possible that year to identify every frog at P3 because of the density and height of the vegetation. Because of this, only P1 and P2 were included when analyzing data from 2016. In 2019, ponds were surveyed in the reverse order, P3 then 2 then 1 and the vegetation was less dense, allowing a more complete record to be made of the frogs at P3. Because there was a focus in 2019 on breeding success, a major effort was made to locate and record all mating pairs and completed nests. This required a more intensive survey strategy: each pond was visited several times over the night from 21:00 $\mathrm{h}$ to 03:00 $h$, to ensure that each frog had been located.

Once located, each frog was removed from its perch and its throat markings, as described by Smith et al. (2019), were photographed and measured in the field. Its snout-vent length (SVL) was measured using dial calipers (accurate to $0.1 \mathrm{~mm}$ ) and its mass measured using an electronic balance (accurate to $0.1 \mathrm{~g}$ ). In 2016, frogs were held for photography by one observer, with the ventral surface facing upwards to allow it to be photographed by a second observer. In 2019, we found that the frogs would perch on the fingers of an open hand, with their throat markings easily visible for photography. This method appeared to be less stressful for the frogs. Photographs were taken using a flash, to ensure a standardized level of illumination, at as similar an angle as possible to allow comparability of images. Photographs were then stored electronically. Depending on the time of night when observations were completed, identification of individual frogs was made back in the laboratory that night or next morning, using the accumulating database of photographs. It was not always possible to identify frogs because, on occasion, the photographs were too indistinct. In addition, particularly at $\mathrm{P} 3$, a few frogs perched in inaccessible places and could not that night be identified. In both years, frog-handling time lasted for always less than one minute. After all records were taken, each frog was returned to its original perch.

In order to assess whether individual frogs exhibited pond and perching site fidelity, a map was made of each pond and the location where each frog was found each night was noted. The maps showed pond length measurements and the positions of landmarks such as plants and rocks; heights above water were measured with a measuring tape to the nearest $1 \mathrm{~cm}$.

\section{Breeding Success}

When a pair in amplexus was seen, it was checked every 10 minutes. Once the male had disengaged and moved away, he was captured to record his identification, mass and SVL. The female was observed until she had completed the nest: she was then captured and her biometric and identification data were also recorded. Each nest was flagged with an orange ribbon and left in place for six days. It was then collected and brought to our laboratory where incubation continued at ambient temperature until hatching, with the nest suspended above a plastic tank 
containing water to a depth of $4 \mathrm{~cm}$. After hatching, the numbers of live tadpoles, dead tadpoles and undeveloped eggs were recorded, and live tadpoles were returned to their pond of origin.

\section{General Observations}

Any notable observations, such as aggressive encounters between males, presence of potential predators, and presence of metamorphosing individuals were noted during the general surveys.

\section{Weather Records}

In 2016, temperature and relative humidity were recorded each night when surveys began using a digital hygro-thermometer (Xintest HTIL). Rainfall was assessed qualitatively as zero, low, medium and high. On 'high' rainfall days, the rain lasted for five or more hours, with varying levels of intensity; 'medium' rainfall involved a shower or showers lasting 2-4 hours; 'low' rainfall included showers of 1-2 hours; 'zero' could include a trace of rain from a shower lasting a few minutes only. In 2019, temperature and relative humidity were not measured, but a rainfall gauge was set up in the Centre's garden, in a location unaffected by trees. Rainwater was collected through a $12 \mathrm{~cm}$ diameter funnel and measured each morning at 09:00 $\mathrm{h}$, then the volume converted to a daily value in $\mathrm{mm}$.

\section{Data Analysis}

Male body condition was calculated by dividing body mass by SVL (Jayson et al. 2018). All statistical analyses and model selections were conducted in $\mathrm{R}$ Studio version 3.6.1 ( $\mathrm{R}$ Core Team 2019). A one-way ANOVA was conducted to compare the breeding site attendance over the first and last 20 days of surveying in 2016 and in 2019 respectively. Male body condition was analyzed using a t-test to compare the body condition of males that attended the breeding site for only one day with males that attended for five or more days in 2019. One-way ANOVA's were used to compare the number of frogs in attendance and the amount of rain $(\mathrm{mm})$ that had fallen on the night of surveying, the number of appearances of individual frogs and the number of nests fathered by each frog and, finally, the number of tadpoles hatched from each nest compared to the body condition of the father.

\section{Results}

\section{Male and Female Attendance}

In 2016, over 53 consecutive nights we identified 43 adult males and 17 adult females. Of these, four males and two females had been encountered among the 54 frogs identified during the pilot study in 2015. In 2019, we identified 47 males and 17 females, with no frogs from the 2016 survey re-appearing. The operational sex ratios (OSR) were 0.40 (2016) and 0.36 (2019) respectively. Numbers and operational sex ratio (ratio of females to males at the breeding site during the study) were similar over the two years, although we might have expected more individuals in 2016 because we surveyed all three ponds that year, rather than just two as in 2019.

In both years, there was considerable variation in the number of nights each male attended, with some appearing once only and others many times (Table 1). In 2016, one frog appeared 36 times, $68 \%$ of the surveyed nights; the highest attendance in 2019 was 15 nights (29\%). Of the male frogs first encountered in 2015, two were frequent attenders in 2016 (36 and 16 nights) whereas two were seen only two and three times respectively. These 2015 frogs all first appeared during the first week (14 to 18 June) of the 2016 study. A limitation regarding our data is the number of unidentified frogs, 2.8 per night on average in 2016. This was due either to poor photographs or to some frogs being inaccessible. There were also unidentified frogs in 2019, although they were not counted due to the different objectives of each sampling season. 
Table 1. Frequencies of breeding site attendance by male and female Phyllomedusa trinitatis at Simla over two years. The first column gives the numbers of nights attended, and the 2016 and 2019 columns show the numbers of frogs in the two years that attended for the different numbers of nights.

\begin{tabular}{|c|c|c|}
\hline Number of nights & 2016 & 2019 \\
\hline \multicolumn{3}{|l|}{ Males } \\
\hline 1 & 12 & 15 \\
\hline 2 & 4 & 4 \\
\hline 3 & 2 & 8 \\
\hline 4 & 2 & 1 \\
\hline 5 & 3 & 4 \\
\hline 6 & - & 5 \\
\hline 7 & 1 & 2 \\
\hline 8 & 1 & 2 \\
\hline 9 & 1 & - \\
\hline 10 & 1 & 1 \\
\hline 11 & 1 & 1 \\
\hline 12 & 1 & - \\
\hline 13 & 1 & 2 \\
\hline 14 & 2 & - \\
\hline 15 & - & 1 \\
\hline 16 & 3 & 1 \\
\hline 17 & 2 & - \\
\hline 20 & 2 & - \\
\hline 23 & 1 & - \\
\hline 27 & 1 & - \\
\hline 30 & 1 & - \\
\hline 36 & 1 & - \\
\hline Total & 43 & 47 \\
\hline \multicolumn{3}{|l|}{ Females } \\
\hline 1 & 11 & 13 \\
\hline 2 & 5 & 2 \\
\hline 3 & 1 & 2 \\
\hline Total & 17 & 17 \\
\hline
\end{tabular}

In 2016, most males were faithful to a particular pond. Of the frogs that attended more than once $(N=38), 25$ appeared only at P1 and five at P2, with eight frogs appearing at both ponds on different nights (six predominantly at P1; only two mainly at P2). In 2019, of the males which attended more than once $(N=32), 22$ appeared at only one pond; the other 10 appeared at two ponds, but never at all three, and usually with a strong preference for one of the ponds. For example, one frog appeared 15 times at P3, and once at P1; another, 12 times at P1 and once at P3. Of the frogs that attended at more than one pond, five used P3 and 2; four used P1 and 3; and one used P1 and 2. We did collect data on the perch sites used by male frogs, in order to test whether they showed strong positional preferences, but we have not presented those data here.

The overall data on male attendance frequencies become more revealing when we analyze individual attendance patterns. In both years, similar patterns were seen in the first appearances of individual males, with about half of the frogs first appearing in the first 10 days, and the remainder at some point over the next six weeks (Table 2). Clearly, for late arrivals, the opportunities for multiple attendances during the study period were limited. For example, in 2016, two frogs were first seen on the final night of the study period, and so are reported in Table 1 as appearing only once. However, some frogs were first recorded early in the study period and only attended once (six frogs in the first 10 days in 2016; seven in 2019); this is considered in the Discussion.

The patterns of attendance by those frogs attending more than once were highly variable (Table 3). Some attended every night over a substantial period (the longest was for a 2016 frog; 19 nights). Others interspersed long gaps in their attendance sequences (one 2016 frog had 15 and 20 day gaps in an attendance sequence of seven appearances over 46 nights). Table 3 shows that some frequent attenders were being recorded until near the end of the study period, while others showed a substantial number of absent nights after their final appearances. 
Breeding site attendance and breeding success in Phyllomedusa trinitatis

Table 2. Proportions (\%) of male Phyllomedusa trinitatis appearing for the first time at the Simla ponds over the progress of the studies in 2016 and 2019, with study days divided into 10-day periods. 2016, $N=43$; 2019, $N=47$ male frogs.

\begin{tabular}{ccccccc}
\hline \multirow{2}{*}{ Year } & \multicolumn{9}{c}{ Study days } \\
\cline { 2 - 7 } & $1-10$ & $11-20$ & $21-30$ & $31-40$ & $41-50$ & $51-$ end \\
\hline $\mathbf{2 0 1 6}$ & 57 & 25 & 12 & 3 & 0 & 3 \\
$\mathbf{2 0 1 9}$ & 49 & 30 & 7 & 7 & 2 & 5 \\
\hline
\end{tabular}

Table 3. Attendance patterns for male Phyllomedusa trinitatis attending the Simla ponds on 10 or more occasions over the two years.

\begin{tabular}{|c|c|c|c|c|}
\hline Frog ID code & $\begin{array}{l}\text { Number of } \\
\text { appearances }\end{array}$ & $\begin{array}{l}\text { Days from first to last } \\
\text { appearance }\end{array}$ & Longest gap & $\begin{array}{c}\text { Days from last appearance to } \\
\text { study end }\end{array}$ \\
\hline \multicolumn{5}{|l|}{2016} \\
\hline 91 & 30 & 41 & 5 & 12 \\
\hline 81 & 24 & 49 & 6 & 4 \\
\hline 95 & 16 & 44 & 12 & 9 \\
\hline 109 & 15 & 24 & 4 & 29 \\
\hline 71 & 12 & 48 & 15 & 4 \\
\hline 94 & 36 & 49 & 5 & 3 \\
\hline 99 & 12 & 33 & 13 & 18 \\
\hline 112 & 20 & 51 & 8 & 0 \\
\hline 56 & 27 & 49 & 9 & 0 \\
\hline 86 & 15 & 38 & 24 & 1 \\
\hline 99 & 14 & 22 & 4 & 27 \\
\hline 91 & 16 & 40 & 13 & 8 \\
\hline 113 & 17 & 18 & 2 & 30 \\
\hline 111 & 17 & 46 & 7 & 1 \\
\hline 71 & 20 & 46 & 5 & 0 \\
\hline 63 & 12 & 39 & 22 & 4 \\
\hline 72 & 11 & 27 & 9 & 0 \\
\hline \multicolumn{5}{|l|}{2019} \\
\hline 6 & 10 & 39 & 17 & 16 \\
\hline 3 & 13 & 37 & 8 & 18 \\
\hline 1 & 16 & 51 & 9 & 3 \\
\hline 5 & 11 & 47 & 15 & 3 \\
\hline 2 & 15 & 31 & 5 & 18 \\
\hline 4 & 13 & 39 & 8 & 7 \\
\hline
\end{tabular}


As expected, attendance by individual females was much less frequent than for males (Table 1). Most appeared only once, but in both study years, a few attended two or three times. When a female attended twice many days apart, the interval between appearances ranged from 19 to 42 days (mean \pm SD: $27.6 \pm 7.0, N=7$ ). In two cases, females appeared two or three times in a short period. In the first, the female appeared on three successive nights (nesting not recorded); in the second, the female appeared twice three nights apart and produced two egg clutches, the first of 323 eggs, the second only 119.

\section{Factors Influencing Male Attendance Patterns}

Season Progression.-Table 4 shows changes in male and female attendance over the study period in both years. In 2016, there was a clear decline in the mean nightly attendance by males, when we compare the first 20 days with the final 20 days (ANOVA: $\mathrm{F}_{(1,38)}: 58.05$, $\operatorname{Pr}(<\mathrm{F}):>0.0001)$, but there was no statistically significant trend in 2019 (ANOVA: $\mathrm{F}_{(1,38)}: 1.76$, $\operatorname{Pr}(<F)$ : 0.19), when nightly attendance was never as high as in the early days in 2016. The number of females declined over the course of the study in both years, while the number of nights with zero females increased with time.
Predation.-We never observed a predation event on any of the frogs, but we did observe potential predators. Bothrops asper (Garman, 1883) (Fer-de-lance; Murphy 1997), including large and small individuals, were seen close to all three ponds, active at night on eight occasions in 2016 and on four occasions in 2019. Another unidentified snake was seen moving around the edge of a pond in 2019. Individuals of the large teiid lizard Tupinambis teguixin (Linnaeus, 1758), known locally as the Tegu Lizard (Murphy 1997), were also frequently observed at the site in all years.

Male Body Condition.-We analyzed body condition in relation to days since first appearance in the six males that attended 10 or more times over the study period in 2019. Body condition ranged between 0.2 and $0.3 \mathrm{~g} / \mathrm{cm}$, but no clear pattern emerged; in particular, there was no sign of a decline over time or appearances. Another possible role for body condition could be that males embarking on a series of appearances are in better condition than those electing to appear only once. However, a comparison of initial body condition of the males which appeared five or more times with those which appeared only once in 2019 found no significant difference (t-test: $\mathrm{T}_{(27.837)}:-0.09, p=0.92$ ).

Weather.-In 2016, temperatures at night mostly ranged from 23 to $25^{\circ} \mathrm{C}$, very occasionally

Table 4. Mean male and total female Phyllomedusa trinitatis attendance numbers at Simla as field seasons progressed (divided into consecutive 10-day periods: total nights $=53$ in 2016; 56 in 2019).

\begin{tabular}{|c|c|c|c|c|c|c|}
\hline \multirow{2}{*}{$\begin{array}{l}\text { Study period } \\
\text { (nights) }\end{array}$} & \multicolumn{2}{|c|}{ Mean nightly males } & \multicolumn{2}{|c|}{ Total females } & \multicolumn{2}{|c|}{ Nights with zero females } \\
\hline & 2016 & 2019 & 2016 & 2019 & 2016 & 2019 \\
\hline $1-10$ & 13.9 & 4.7 & 10 & 10 & 4 & 4 \\
\hline $11-20$ & 13.6 & 3.3 & 10 & 6 & 5 & 7 \\
\hline $21-30$ & 11.4 & 4.0 & 8 & 5 & 6 & 7 \\
\hline $31-40$ & 5.1 & 5.6 & 0 & 7 & 10 & 7 \\
\hline $41-53(56)$ & 6.3 & 2.3 & 5 & 1 & 9 & 12 \\
\hline Totals & & & 33 & 29 & 34 & 37 \\
\hline
\end{tabular}


reaching $28^{\circ} \mathrm{C}$. Relative humidity was always high, usually ranging between $80-100 \%$. Daily rainfall ranged from zero (24 days), to low (9 days), medium (7 days) and high (12 days). There was no statistically significant relationship between any of these variables and the nightly number of males attending. In 2019, rainfall ranged from zero or trace ( 22 days) to $45 \mathrm{~mm}$. Only four days over the study period had rainfall over $20 \mathrm{~mm}$. There was a significant positive relationship (ANOVA: $\mathrm{F}_{(1.51)}: 8.58, \operatorname{Pr}(<\mathrm{F}): 0.005$ ) between the nightly total of attending frogs (males and females) and rainfall. However, it was noticeable that after the heaviest day of rainfall, only one frog appeared, suggesting that exceptional rainfall may deter frogs, while moderate amounts attract them. There were two sequences of several days $(3,4)$ without rain, and on both occasions, no frogs attended on the night following such a sequence.

\section{Breeding Success, Competition and Tadpoles}

In 2016, 32 cases of amplexus were recorded, but male identity was not known in enough cases to allow for an analysis. In 2019, we were able to relate 19 nests to particular males. Of these, one male had three successes and three had two, and there was a significant positive relationship between appearances at the breeding site and nest number (ANOVA: $F_{(1,29)}: 7.44, \operatorname{Pr}(<F): 0.01$ ). However, if we relate the likelihood of nesting to the number of appearance nights for the male population overall (number of nests made, divided by the number of frogs making those nests multiplied by the number of nights these frogs attended the breeding site), the likelihood of success was as high or higher for frogs which appeared only once as it was for frogs which attended often (Table 5).

Interference in amplexus by additional males was observed both in 2016 and in 2019. In 2019, from 22 amplexus events recorded, nine (41\%) were subject to interference by one or more additional males with the second male dislodging the first on at least one occasion. In addition, pseudo-amplexus between groups of two or more males (up to six males) was occasionally seen.

We recorded the number of tadpoles produced in 19 nests (range 54-487) where we knew the identity and body condition of the male. The data suggested a positive relationship between body condition and tadpole number (ANOVA: $\mathrm{F}_{(1,17)}$ : 4.09, $\left.\operatorname{Pr}(<\mathrm{F}): 0.059\right)$. In 2019, Phyllomedusa trinitatis breeding had occurred before our arrival on site in early June, since tadpoles were visible in P1 by then. Metamorphic individuals were observed sitting on leaves around the pond by 22 July (Figure 1).

Table 5. Relationship of breeding site attendance by male Phyllomedusa trinitatis at Simla to number of nests produced by these frogs (2019).

\begin{tabular}{lccc}
\hline Appearances (a) & Number of frogs $(\mathbf{b})$ & Number of nests (c) & Nests per attendance night (c/ab) \\
\hline 1 & 14 & 3 & 0.21 \\
2 & 4 & 1 & 0.13 \\
3 & 8 & 1 & 0.04 \\
$4-5$ & 5 & 2 & 0.08 \\
6 & 5 & 2 & 0.07 \\
$7-8$ & 4 & 4 & 0.13 \\
$10-16$ & 6 & 6 & 0.08 \\
15 & 1 & 3 & 0.20 \\
\hline
\end{tabular}




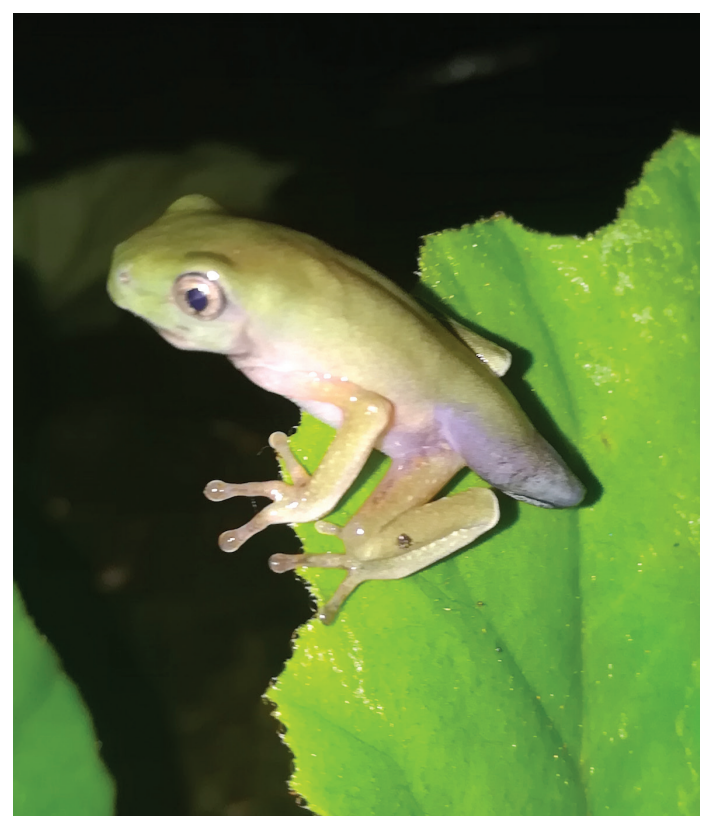

Figure 1. Metamorphosing Phyllomedusa trinitatis on a leaf beside a pond. Both images taken at the William Beebe Tropical Research Centre (Simla).

\section{Discussion}

There are few previous published studies on the breeding strategies of phyllomedusine frogs, and even fewer that have followed the behavior of identified individuals over extended times. In our study, we used a naturally occurring individually variable throat marking in $P$. trinitatis (Smith et al. 2019) to follow the reproductive behavior of individuals in a set of three ponds, all within $60 \mathrm{~m}$ of each other. We followed frog attendance patterns for 22 nights in a pilot year (2015), then over 52 consecutive nights in 2016 and 56 nights in 2019. A small number of both males and females first identified in 2015 reappeared in 2016, but not in 2019, providing some estimate of longevity.

\section{Female Attendance}

Since at least some males attended each pond every night, females could be sure to encounter a potential mate. Considering that we recorded cases of females attending on two nights in succession, it is likely that females exercise some choice, and attend on a second night following a lack of success. The example where a female laid two clutches, the first large and the second smaller, only three days apart, may be a case of a female exercising choice as a reproductive strategy. We also recorded seven females over the two main study years that attended twice with a mean interval of 27.6 days. This provides an estimate of the internesting interval in these frogs, on the assumption that females only attend the breeding site when ready to spawn that night or soon thereafter (we observed spawning in some but not all of these cases). This is a variable that has rarely been reported in phyllomedusines. Kenny (1966) reported a marked female $P$. trinitatis that bred at least three times over a season (June, July and October), but he did not record the internesting intervals. Wogel et al. (2006) reported intervals of 26, 32 and 60 days between matings by three female Pithecopus rohdei (Mertens, 1926), but since they did not monitor the population every night, we cannot be sure that all these figures represent inter-nesting intervals. The ability of female anurans in continuous mating systems to produce multiple clutches over a breeding season has not often been measured.

The operational sex ratios (OSR) in our study were 0.40 (2016) and 0.36 (2019) respectively. Wogel et al. (2006) reported an OSR of 0.48 for $P$. rohdei and Oliveira et al. (2012) 0.42 for Pithecopus megacephalus (Miranda-Ribeiro, 1926), both similar to our results, with over twice as many males as females. The exceptional result is that of Borges et al. (2018) with an OSR of only 0.09 in their study on Pithecopus ayeaye Lutz, 1966. In our study, females were absent from the set of ponds on 64\% (2016) and 66\% (2019) of nights respectively, similar to the proportion (62\%) in the study of Wogel et al. (2006) on P. rohdei. 


\section{Male Attendance}

Pond fidelity was high, with only a minority of frogs occasionally appearing at a second pond. Attendance frequency by individuals was also highly variable, with a few attending on many nights over the study period, but others only occasionally and some only once. A study by Green et al. (1990) tracked the movements of individual Túngara frogs [Engystomops pustulosus (Cope, 1864)] over 10 days during the breeding season. They found that some calling occurred every night over the study period, but that individual males varied greatly in their attendance patterns: some called each night over an 11-day period; others called on as few as three nights, a result that agrees with our findings. The results of a feeding experiment suggested that individual attendance patterns were not related to energy constraints. Males tended to join larger choruses, possibly to reduce predation risk, as the likelihood of a predator choosing a given frog would be lower than in a small chorus. Green et al. (1990) also found that attendance was influenced by rainfall and temperature.

We found no influence related to energy constraints, in the sense that changes in body condition showed no relationship to attendance. We have no data on calling, but our experience is that Phyllomedusa trinitatis calls are quiet and infrequent and sporadic enough not to be useful in locating individuals and would not result in high rates of energy expenditure (JRD pers. obs.). Results on breeding site fidelity from other studies on male phyllomedusine frogs also generally show high but not complete fidelity (Wogel et al. 2006, Dias et al. 2017, Borges et al. 2018), suggesting that the unpredictable attendance of females may lead to variable behavior amongst males. This could be particularly the case where several breeding sites occur over a relatively small area, as at our site at Simla.

In one year, we found a positive correlation between rainfall and attendance, while sequences of days with no rain resulted in a drop in attendance. Neither temperature nor humidity appeared to have any influence, but these are rather stable at the study site, with little variation in nighttime temperature, and humidity always high. Rodrigues et al. (2007) found an interesting difference in the relationship between matings and weather in a comparison between Pithecopus azureus (Cope, 1862) and Phyllomedusa sauvagii Boulenger, 1882. Pithecopus azureus were found to mate throughout the rainy season irrespective of actual rainfall, whereas $P$. sauvagii only mated on nights following heavy rain, or the one to two following nights.

When considering factors responsible for the observed attendance patterns, one possibility is that as the breeding season progresses, the number of attending males declines. If this were so, the underlying causes could be predation, or anticipated lack of females, or some factor related to changes in body condition, for instance sperm depletion. Frogs appearing for the first time late during the study seasons, in late July or early August, were most likely recruits to the adult population from previous years. We do not know the time it takes to reach adulthood in this species in the wild, but Smith et al. (2019) reported that captive-reared individuals could reach adulthood about one year after metamorphosis. If this is the case in the wild, recruits from the previous year should be entering the adult population from late July onwards. The finding of the first metamorphs from 2019 spawning in mid-July fits with this scenario. Indirect support for this argument can be drawn from the fact that all the frogs identified in 2015 that re-appeared in 2016 did so within the first week of the study. Another explanation could be that after attending a few times individuals then dispersed to other breeding locations, but as there are no other breeding sites located locally and individuals that appeared once or only a few times were not seen in subsequent years (unpubl. data) we believe this explanation is unlikely. A more likely explanation is predation. We never observed predation on 
Phyllomedusa trinitatis, but snakes known to prey on frogs (Bothrops asper; Farr and Lazcano 2017) and Large Tegu lizards (Tupinambis teguixin; Murphy 1997) were commonly encountered in the vicinity of the ponds, and other predators are possible, such as owls and bats: the frog-eating bat Trachops cirrhosus (Spix, 1823) occurs in Trinidad, although $P$. trinitatis adults are larger than its usual prey (Gomes and Reid 2015). Ffrench (1991) lists several owl species that occur in Trinidad as preying on frogs. We suggest that predation is the most likely explanation for male frogs that attended once or a few times near the start of the study periods, and never again over several weeks. .

\section{Mating Success and Competition}

Several previous studies have demonstrated a relationship between breeding site attendance and male mating success. Ryan (1983) found males attended on average 7.2 nights over a period of 43 days, and the more frequent attenders achieved the most matings. Greer and Wells (1980) followed male glass frog attendance over 30 nights: there was a significant positive relationship between attendance nights and the number of successful matings. Glass frog attendance patterns showed some similarities to our findings on $P$. trinitatis: some individuals attended on up to 10 consecutive nights; others left the area for 1-18 nights before returning to their original territories. Although we found a relationship between attendance and mating success, it was not at all clear that frequent attendance was the best strategy.

We found that amplectant pairs were often interrupted by one or more additional males which either joined in the amplexus or attempted to dislodge the original male. We do not have data on how often these efforts were successful in terms of fertilizing eggs. Presumably, the occurrence of such competition events is related to the number of unmated males in the vicinity when a pair forms. This kind of interference competition has often been reported in other phyllomedusine species (Wogel et al. 2005, Oliveira et al. 2012, Dias et al. 2017), where attempts to displace the original male have been reported as generally unsuccessful; however, we are not aware of any results indicating the relative genetic contributions of initial compared to competitor males in phyllomedusine frogs.

\section{Conclusion and Limitations}

Our study takes a deep dive into the behaviors of Phyllomedusa trinitatis when attending breeding sites. As our data was collected over two non-consecutive years, this gives us an interesting insight into how repeatable attendance patterns are for the individual and the overall population. We found that females will usually only attend a breeding site once but that males will often attend multiple times and show high pond fidelity, seemingly with a strong preference. We were able to identify three attendance patterns among males: attend for multiple consecutive nights, attend once, attend on multiple non-consecutive nights, but none of these attendance patterns appeared to be optimal for breeding success. We identified that rainfall does influence attendance but that the number of night attending a breeding site does not impact male body condition.

We hope that our results will stimulate further research into Phyllomedusa mating patterns, using the non-invasive individual recognition method reported by Smith et al. (2019). An avenue not explored within this paper is the link between breeding site attendance and animal personality, a subject area that we believe would lend itself well to this study system, perhaps providing an explanation for the behaviors that we see here. A limitation of our work was the number of frogs we failed to identify, caused by the density of vegetation in some parts of the habitat: however, we do not think that the missing data compromised our conclusions. 


\section{Acknowledgments}

We thank staff and students on the University of Glasgow's Trinidad Expeditions in 2015, 2016 and 2019 for help with fieldwork, and multiple agencies for assistance from small grants, notably the University of Glasgow's Chancellor's Fund, Glasgow Natural History Society, Denis Curry's Charity, the Thriplow Trust and the Gilchrist Educational Trust. We also thank the Asa Wright Nature Centre for providing accommodation at Simla, and especially curators Ronnie and Rupert for their help. The Trinidad Government's Wildlife Section through Anna Bandoo kindly provided permits for our work in all three years.

\section{References}

Aichinger, M. 1992. Fecundity and breeding sites of an anuran community in a seasonal tropical environment. Studies on Neotropical Fauna and Environment 27: 9-18.

Borges, M. M., R. C. Nali, B. F. Fiorillo, and C. P. A. Prado. 2018. Site fidelity, reproductive behavior and investment in the Brazilian Reticulate Leaf Frog, Pithecopus ayeaye Lutz, 1966 (Anura: Phyllomedusidae). Herpetozoa 31: $61-68$.

Dias, T. M., T. G. Santos, F. P. Maragno, V. F. Oliveira, C. Lima, and S. Z. Cechin. 2017. Breeding biology, territoriality, and reproductive site use by Phyllomedusa iheringii (Anura: Phyllomedusidae) from the South American pampa in Brazil. Salamandra 53: 257-266.

Downie, J. R., M. Nokhbatolfoghahai, D. Bruce, J. M. Smith, N. Orthmann-Brask, and I. MacDonald-Allan. 2013. Nest structure, incubation and hatching in the Trinidadian leaf-frog Phyllomedusatrinitatis(Anura: Phyllomedusidae). Phyllomedusa 12: 13-32.

Farr, W. L. and D. Lazcano. 2017. Distribution of Bothrops asper in Tamaulipas, Mexico, and a review of prey items. Southwestern Naturalist 62: 77-84.

Ffrench, R. 1991. A Guide to the Birds of Trinidad and Tobago. Second edition. Ithaca. Comstock Publishing. 426 pp.

Frost, D. R. 2020. Amphibian Species of the World: an Online Reference. Version 6.0 (1 November 2020). Electronic Database accessible at http://research.amnh. org/herpetology/amphibia/American. Museum of Natural History. New York, USA
Given, M. F. 1988. Growth rate and the cost of calling activity in male carpenter frogs, Rana virgatipes. Behavioral Ecology and Sociobiology 22: 153-160.

Gomes, G. A. and F. A. Reid. 2015. Bats of Trinidad and Tobago: A Field Guide and Natural History. Trinidad. NHBS. 286 pp.

Gottsberger, B. and E. Gruber. 2004. Temporal partitioning of reproductive activity in a neotropical anuran community. Journal of Tropical Ecology 20: 271-280.

Gourevitch, E. H. Z. and J. R. Downie. 2018. Evaluation of tree frog tracking methods using Phyllomedusa trinitatis (Anura: Phyllomedusidae). Phyllomedusa 17: 233-246.

Green, A. J. 1990. Determinants of chorus participation and the effects of size, weight and competition on advertisement calling in the tungara frog, Physalaemus pustulosus (Leptodactylidae). Animal Behaviour 39: 620-638.

Greer, B. J. and K. D. Wells. 1980. Territorial and reproductive behavior of the tropical American frog Centrolenella fleischmanni. Herpetologica 36: 318-326.

Jayson, S., L. Harding, C. J. Michaels, B. Tapley, J. Hedley, M. Goetz, A. Barbon, G. Garcia, J. Lopez, and E. Flach. 2018. Development of a body condition score for the mountain chicken frog (Leptodactylus fallax). Zoo Biology 37: 196-205.

Kenny, J. S. 1966. Nest building in Phyllomedusa trinitatis Mertens. Caribbean Journal of Science 6: 15-22.

Kirton, S. 2014. Phyllomedusa trinitatis (Leaf-nesting Frog). The Online Guide to the Animals of Trinidad and Tobago - UWI, pp. 2010-2013.

Lucas, J. R. and R. D. Howard. 1995. On alternative reproductive tactics in anurans: Dynamic games with density and frequency dependence. American Naturalist 146: 365-397.

Lucas, J. R., R. D. Howard, and J. G. Palmer. 1996. Callers and satellites: Chorus behaviour in anurans as a stochastic dynamic game. Animal Behaviour 51: 501518.

McCauley, S. J., S. S. Bouchard, B. J. Farina, K. Isvaran, S. Quader, D. W. Wood, and C. M. St. Mary. 2000. Energetic dynamics and anuran breeding phenology: Insights from a dynamic game. Behavioral Ecology 11: 429-436.

Meuche, I., K. E. Linsenmair, and H. Pörhl. 2011. Female territoriality in the strawberry poison frog (Oophaga pumilio). Copeia 2011: 351-356.

Murphy, J. C. 1997. Amphibians and Reptiles of Trinidad and Tobago. Malabar. Kreiger Publishing. 245 pp. 
Oliveira, F. F. R., P. A. G. Nogueira, and P. C. Eterovick. 2012. Natural history of Phyllomedusa megacephala (Miranda-Ribeiro, 1926) in southeastern Brazil, with descriptions of its breeding biology and male territorial behaviour. Journal of Natural History 46: 117-129.

R Core Team. 2019. R: a language and environment for statistical computing. R Foundation for Statistical Computing. Vienna, Austria. URL http://www.R-project. org/.

Rodrigues, D. J., M. Uetanabaro, and F. S. Lopes. 2007. Breeding biology of Phyllomedusa azurea Cope, 1862 and $P$. sauvagii Boulenger, 1882 (Anura) from the Cerrado, Central Brazil. Journal of Natural History 41: 1841-1851.

Ryan, M. J. 1983. Sexual selection and communication in a neotropical frog Physalaemus pustulosus. Evolution 37: 261-272.

Ryan, M. J., M. D. Tuttle, and L. K. Taft. 1981. The costs and benefits of frog chorusing behavior. Behavioral Ecology and Sociobiology 8: 273-278.

Smith, J. M., A. Bland, E. Gourevitch, P. A. Hoskisson, and J. R. Downie. 2019. Stable individual variation in ventral spotting patterns in Phyllomedusa trinitatis (Anura: Phyllomedusidae) and other Phyllomedusa species: a minimally invasive method for recognizing individuals. Phyllomedusa 18: 13-26.

Ulloa, J. S., T. Aubin, D. Llusia, É. A. Courtois, A. Fouquet, P. Gaucher, S. Pavoine, and J. Sueur. 2019. Explosive breeding in tropical anurans: Environmental triggers, community composition and acoustic structure. BMC Ecology 19: 1-17.

Wells, K. D. 1977. The social behavior of amphibians. Animal Behaviour 25: 666-693.

Wells, K.D. 2007. The Ecology and Behavior of Amphibians. Chicago. The University of Chicago Press. 1148 pp.

Wogel, H., P. A. Abrunhosa, and J. P. Pombal Jr. 2005. Breeding behaviour and mating success of Phyllomedusa rohdei (Anura: Hylidae) in south-eastern Brazil. Journal of Natural History 39: 2035-2045.

Wogel, H., P. A. Abrunhosa and J. P. Pombal Jr. 2006. Chorus organization of the leaf frog Phyllomedusa rohdei (Anura: Hylidae). Herpetological Journal 16: 21-27.

Editor: Ariovaldo A. Giaretta 